\title{
Research on Regional Trunk Logistics Operating Cost
}

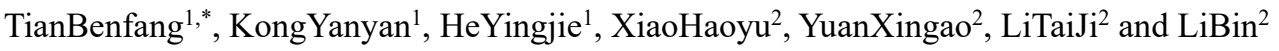 \\ ${ }^{1}$ Logistics Department, Shandong Jiaotong University, Jinan, Shandong Province, 250357, China \\ 2 traffic engineering, Shandong Jiaotong University, Jinan, Shandong Province, 250357, China
}

\begin{abstract}
In order to ensure the balance of trunk transportation resources, logistics enterprises generally require transport vehicles to return to the initial distribution after completing the transportation task, so as to facilitate the next phase of transportation operations. Most logistics enterprises waste the trunk transportation resources in the whole process of logistics transportation. At this time, we need to choose a comprehensive transportation network optimization method to improve the vehicle loading rate, reduce the transportation cost, and design a new form of trunk transportation network. The article analyzes the operation flow of trunk transportation logistics.
\end{abstract}

\section{Introduction}

In recent years, the transportation network of some leading logistics enterprises in China has gradually improved through continuous optimization. Although the total amount of logistics distribution industry in China has developed rapidly, Most logistics companies face common problems: unreasonable transportation structure, low vehicle loading rate, unreasonable vehicle scheduling, especially in trunk logistics transportation network. With the continuous development of our country's economy, the imbalance of regional economic level leads to the imbalance of the flow of goods between regions. Many one-way full-load vehicles have a low loading rate when they return, which greatly increases the transportation cost. Aiming at the deficiency of this research, this paper puts forward the optimization form of transportation network of midway stop mode, which can improve the vehicle loading rate while optimizing the transportation vehicle path, so as to reduce the unit cargo transportation cost. In order to improve the core competitiveness of enterprises, improve the loading rate of transport vehicles and reduce logistics costs, enterprises must improve the existing forms of trunk transportation network, adopt advanced transportation resource management methods, and optimize the trunk logistics transportation network. Improve the operational efficiency of logistics enterprises and vehicle resource utilization.

\section{Analysis on Operation Process of Trunk Transportation Logistics}

Facing the fierce industry competition, logistics enterprises are establishing a relatively perfect operation system to realize the commitment to limitation and quality. After the deployment in recent years, most express

* Corresponding author: 3266156130@qq.com

1652214425@qq.com

348045066@qq.com transportation enterprises have initially completed the development and landing of information management system, routing vehicle system and operating system, and have realized the systematization of multi-node process. Most express transportation enterprises have the conditions to build a relatively perfect operation system. Through combing and optimizing the operation process and management process, the standard operation system is formed, the field operation is guided and standardized, and finally the whole process node monitoring is realized through the systematization of each link process. The logistics transportation network freight flow is shown in figure 1 .

\begin{tabular}{|c|c|c|c|c|}
\hline \multicolumn{5}{|c|}{ Sending outlets } \\
\hline \multicolumn{5}{|l|}{ collection } \\
\hline collection & \multicolumn{4}{|c|}{ Distribution of outlets } \\
\hline $\begin{array}{l}\text { Feeder } \\
\text { service }\end{array}$ & \multicolumn{4}{|c|}{$\begin{array}{l}\text { Network to the distribution of } \\
\text { the handover process }\end{array}$} \\
\hline \multicolumn{5}{|c|}{ Initial distribution } \\
\hline \multicolumn{5}{|l|}{ sorting } \\
\hline \multicolumn{2}{|c|}{ Entry operations } & \multicolumn{3}{|c|}{$\begin{array}{l}\text { Departure } \\
\text { operations }\end{array}$} \\
\hline $\begin{array}{l}\text { To } \\
\text { pieces }\end{array}$ & $\begin{array}{l}\text { address } \\
\text { ee }\end{array}$ & & tributio & $\begin{array}{l}\text { Pull } \\
\text { out }\end{array}$ \\
\hline $\begin{array}{l}\text { Trunk } \\
\text { transport }\end{array}$ & \multicolumn{4}{|c|}{$\begin{array}{l}\text { Distribution to distribution } \\
\text { the handover process }\end{array}$} \\
\hline \multicolumn{5}{|c|}{ Purpose allocation } \\
\hline \multicolumn{5}{|c|}{ sorting } \\
\hline \multicolumn{2}{|c|}{ Entry operations } & \multicolumn{3}{|c|}{$\begin{array}{l}\text { Departure } \\
\text { operations }\end{array}$} \\
\hline $\begin{array}{l}\text { To } \\
\text { pieces }\end{array}$ & $\begin{array}{l}\text { address } \\
\text { ee }\end{array}$ & & tributio & $\begin{array}{l}\text { Pull } \\
\text { out }\end{array}$ \\
\hline $\begin{array}{l}\text { Feeder } \\
\text { service }\end{array}$ & \multicolumn{4}{|c|}{$\begin{array}{l}\text { Distribution of the network } \\
\text { handover process }\end{array}$} \\
\hline \multicolumn{5}{|c|}{ Distribution outlets } \\
\hline \multicolumn{5}{|c|}{ send } \\
\hline \multicolumn{3}{|c|}{$\begin{array}{l}\text { Network to receive } \\
\text { the distribution }\end{array}$} & \multicolumn{2}{|l|}{ delivery } \\
\hline
\end{tabular}

Fig. 1. Schematic illustration of freight flow in a transport network. 
The logistics transportation network is mainly divided into trunk transportation network and branch transportation network. Because the whole transportation network system is more complex, this paper mainly introduces the trunk transportation network, and the branch transportation network does not do too much. The operation process of trunk transportation network mainly includes distribution of goods, goods in transit, distribution of goods received.

\subsection{Distribution to distribution processes}

(1) Distribution of distribution vehicles

The process of distribution and distribution includes: system dispatching, dispatching inspection, reassigning and dispatching.

(2) Distribution of distribution to port

The process includes: waiting for vehicles, confirmation of arrival, allocation of berths, guidance to port and port.

(3) Distribution and distribution of vehicles

The process includes: dispatch of work order, group of personnel, dispatch of work order, scanning task code, loading scan, loading code, and completion of work order.

(4) Departure of allotments

The process of departure includes: vehicle seal, document transfer, departure attendance, exit note distribution and departure distribution.

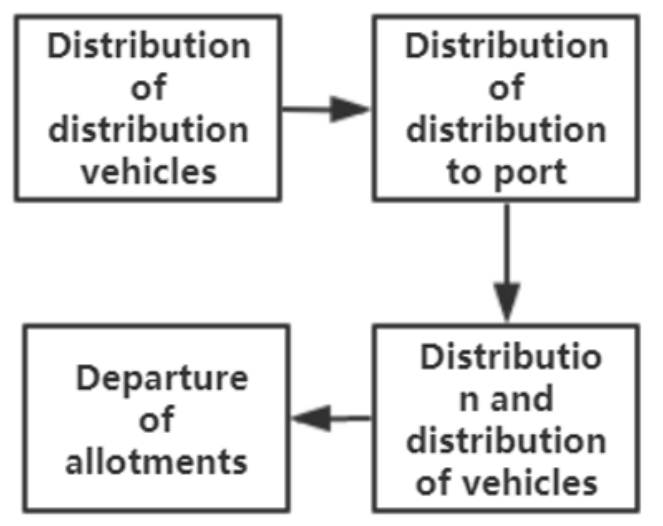

Fig. 2. Distribution to distribution processes

\subsection{Distribution and distribution processes}

(1) Tracking of inbound vehicles

In-transit vehicle tracking process includes: departure time check, in-transit tracking, actual arrival.

(2) Allocation of attendance to the assigned collection The process includes: vehicle arrival, incoming attendance, document handover, unsealing.

(3) The port of destination for the distribution

The process includes: waiting by port, distributing berths, guiding port and port.

(4) Distribution of vehicles to be unloaded

The process includes: work order dispatch, personnel group, personnel group, unloading scan, pallet group, problem report, work order completion.

(5) Distribution of incoming and outgoing

The process of departure includes: departure berth, departure attendance distribution.

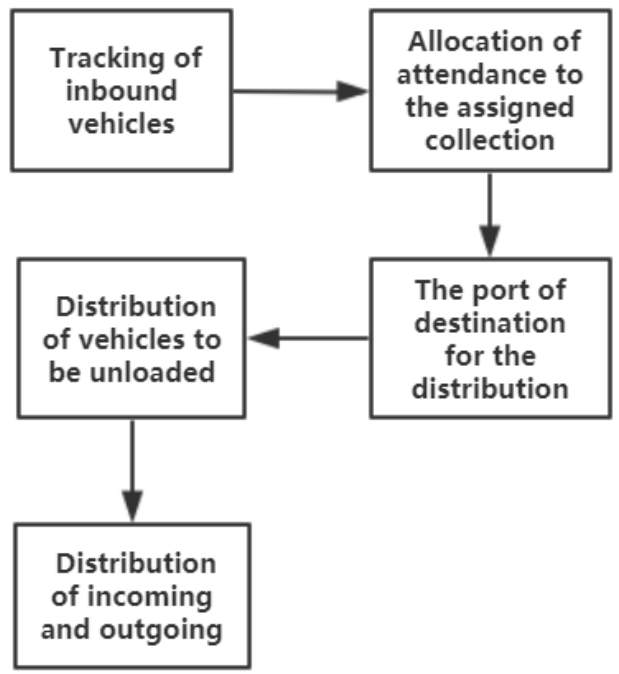

Fig. 3. Distribution and distribution processes

\section{Cost logistics operation cost analysis}

Transportation cost is the sum of all expenses incurred by transportation to complete passenger and freight transportation, and the main component of transportation product value. The important index to measure the quality of transportation work and to assess the management level of transportation enterprises is also the basis for the rational formulation of transportation prices. Generally by wages, materials, fuel, electricity, repair and depreciation, business management fees and other expenses. Among them, the proportion of materials is small, some even do not. Fuel costs, repairs and depreciation are significant. In practical work, the total amount of transportation expenditure is often called "total transportation cost ", and the transportation expenditure borne by unit transportation products is called" unit transportation product cost ".

\subsection{Distance-related costs}

Logistics costs related to transportation distance mainly include vehicle maintenance, fuel, tire. The total cost associated with distance is equal to the transportation distance multiplied by the related cost per kilometer.

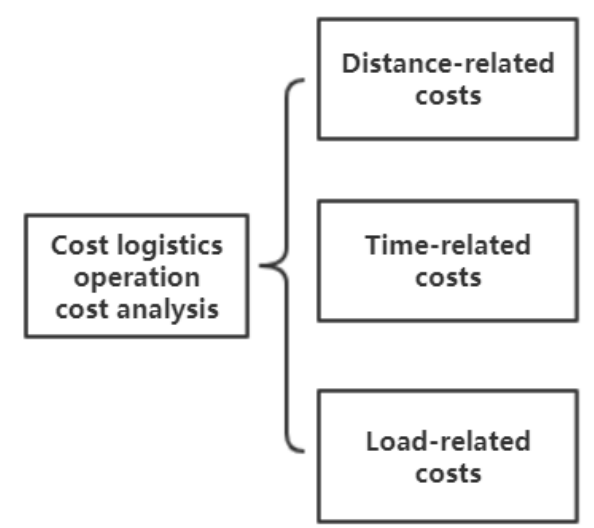

Fig. 4. Cost logistics operation cost analysis 
(1) Fuel costs $C^{\mathrm{F}}$

Fuel costs can be calculated by investigating the fuel consumption per kilometer of vehicle per vehicle for each model and the fuel price per liter (regardless of the rise and fall of fuel prices), and the fuel cost per kilometer is: $\mathrm{C}^{\mathrm{F}}=$ fuel price $/ \mathrm{l} \times$ fuel consumption $/ \mathrm{km}$

(2) Tire fees $C^{S}$

The tire will inevitably wear and tear in the course of transportation, which will result in tire cost. Tire costs are mainly determined by the number of tires, tire prices and tire mileage. The tire cost per kilometer is: $\mathrm{C}^{\mathrm{S}}=($ vehicle tire quantity $\times$ tire price / number)/ tire mileage

(3) Maintenance costs $C^{R}$

Vehicle maintenance fee refers to the company's transport vehicles for occasional maintenance and maintenance costs. Vehicle maintenance costs per kilometer are $\mathrm{C}^{\mathrm{R}}=($ total maintenance $\operatorname{cost} /$ year $) /($ total distance/year)

Summary of the above types of costs, the distancerelated freight cost coefficient $C^{D}$ (yuan / km) is: $C^{D}=C^{F}$ $+\mathrm{C}^{\mathrm{S}}+\mathrm{C}^{\mathrm{R}}$

\subsection{Time-related costs}

The cost related to transportation time mainly includes vehicle depreciation cost, vehicle insurance cost, personnel cost (driver), road maintenance cost. The total cost associated with time is equal to the number of days transported times the daily cost.

Daily vehicle transportation costs include daily vehicle depreciation costs, vehicle insurance costs, personnel costs, road maintenance costs.

(1) Depreciation $C^{\mathrm{E}}$

Depreciation cost of vehicles per day $\mathrm{C}^{\mathrm{E}}=($ new vehicle value-residual value)/ useful life /365

(2) Vehicle insurance $\mathrm{C}^{\mathrm{I}}$

Daily vehicle insurance premium: $\mathrm{C}^{\mathrm{I}}=$ annual premium $/ 365$

(3) Road maintenance $\mathrm{C}^{\mathrm{H}}$

Road maintenance fee refers to the responsibility and obligation of enterprises to pay road use fees to relevant departments when using roads built by the state. Daily road maintenance costs: $\mathrm{C}^{\mathrm{H}}=$ monthly road maintenance costs $/ 30$

(4) Staff costs $C^{M}$

The personnel cost is mainly the driver's salary and the attendant's salary. Staff costs per day: $\mathrm{C}^{\mathrm{M}}=$ number of personnel required per vehicle $\times$ (total annual salary of personnel) $/ 365$

Summary of the above types of costs, time-related freight cost coefficient $\mathrm{C}^{\mathrm{T}}$ ( yuan / day) is: $\mathrm{C}^{\mathrm{T}}=\mathrm{C}^{\mathrm{E}}+\mathrm{C}^{\mathrm{H}}+\mathrm{C}^{\mathrm{M}}$

\subsection{Load-related costs}

The cost related to the weight of the goods mainly includes the crossing fee, the labor cost of loading and unloading the goods at the stop.

tolls for crossing the bridge $\mathrm{C}^{\mathrm{B}}$

Crossing fee refers to when a company's vehicle passes a road or bridge built by a group or individual or a country. The fee to be paid. The cost of crossing the bridge per ton of goods is: $\mathrm{C}^{\mathrm{B}}=$ Total cost of crossing/load

(2) labor costs $C^{\mathrm{L}}$

Cost of labor refers to the cost of labor incurred in the loading and unloading of cargo on a stop-out basis. The cost of labor per ton of cargo is: total cost of $\mathrm{C}^{\mathrm{L}}=$ labor/weight of cargo

The above two costs are summarized and the freight cost coefficient associated with load is $\mathrm{C}^{\mathrm{W}}$ (yuan / ton) as follows: $\mathrm{C}=\mathrm{C}^{\mathrm{B}}+\mathrm{C}^{\mathrm{L}}$

theoretically, the unit transport cost (cost per ton $\mathrm{km}$ ) should be a continuous decreasing function, but in fact the truck has a rated load of $2 \mathrm{t}, 6 \mathrm{t}, 8 \mathrm{t}$ and so on, so the unit transport cost of vehicles with different rated loads is different. That is, if the weight of the vehicle is $6.1 \mathrm{t} \sim 8 \mathrm{t}$, the enterprise operation and dispatch department will choose the vehicle with rated load of $8 \mathrm{t}$ for cargo transportation, so the unit transportation cost function of the vehicle with different rated load, as shown in figure 5(a), The higher the vehicle loading rate, the lower the unit cargo transportation cost; the total transportation cost is a continuous increase function with multiple inflection points, as shown in figure 5-(b) below
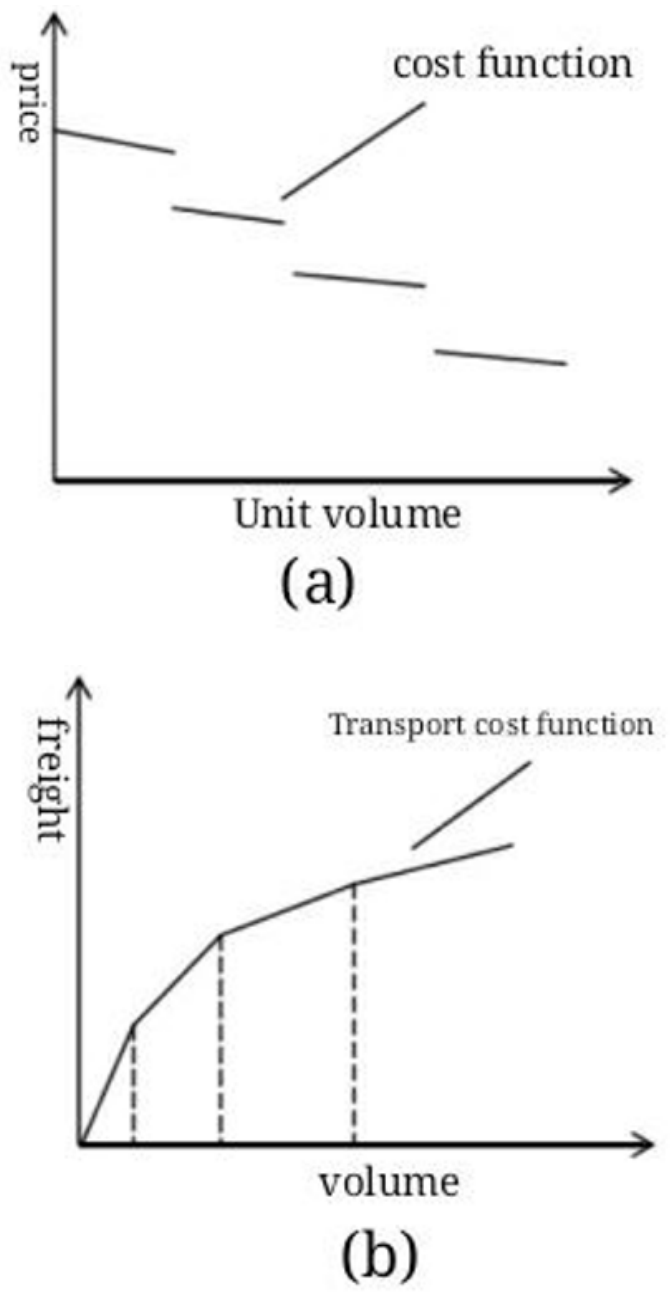

Fig. 5. Cost function of trunk transportation network

The above is the analysis and calculation of the vehicle transportation cost involved in each link in the trunk transportation network of logistics enterprises. The 
logistics cost involved in the logistics transportation process is not all used for model building. For example, the storage cost of goods when they stay in the distribution center is not included in the transportation optimization model because the cost has a small impact on the logistics cost. Therefore, only the key factors affecting the total cost of logistics in the process of trunk transportation are analyzed.

\section{Conclusion}

In view of the practical problems faced by most logistics enterprises in the transportation process, the current trunk transportation network is optimized, and the one-way full load vehicle is proposed to improve the vehicle loading rate through the midway stop mode in the return process. In order to reduce logistics transport costs, improve the competitiveness of enterprises. At present, due to the unbalanced economic development of our country, the flow of goods is extremely unbalanced. Many one-way full-load vehicles in the return process loading rate is not high empty return situation, greatly wasted the transportation resources, makes the logistics enterprise transportation cost high, is not conducive to the enterprise to enhance the core competitiveness. The main purpose of this paper is to improve the loading rate of vehicles and reduce the cost of logistics transportation. Aiming at the different loading and unloading modes of trunk logistics transport vehicles, this paper puts forward the midway stop mode, and compares the empty driving waste of vehicles in two modes: point-to-point direct mode and midway stop mode.

\section{References}

1. Yan Rong. A Study on the Optimization of Transport Network of Regional Trunk Logistics [D].] in China Master thesis. Zhejiang University of Technology. 2018(3)

2. Shi Chun yan, Huang Hui. A Review of Research and Prospect [J].] on Vehicle Routing Logistics technology. 2014(12)

3. $\mathrm{Xu}$ Tao. Design and Implementation of Modern Logistics Transportation Management System [D].]1 Master thesis. University of Electronic Science and Technology. 2013(12)

4. Hu jue liang, Yan Rong. A Study on Stopover of Trunk Transportation Network of Express Delivery Enterprises [J].]; and Journal of Zhejiang University of Technology. 2018(4)

5. Liu Wen pei. A Study on Path Optimization of Dynamic Logistics Network Based on Joint Distribution [D]. Master thesis. Shenyang University of Technology. 2016(5)

6. Yang Guanghua. A Study on Evolution Mechanism and Optimization of Regional Logistics Network Structure [D].]1 Doctoral thesis. Central South University. 2010(5)

7. Ding Linlin. Relaxation of Control and Improvement of Axialoke Networks for Civil Aviation Transport - Based on the Perspective of Comparison between FC Networks and HS Networks Journal of Harbin Commercial University. 2008(6)

8. Yi Zhenghui. [D].] Design and Implementation of Optimal Scheduling System for Logistics Trunk Transportation in Tobacco Industry Master thesis. Hunan University. 2015(3)

9. Ma Yijia. Discussion on Logistics Cost in Direct Transportation Mode [J].];2 Logistics engineering and management. 2010(11)

10. He Liming. A Review of the Development of China's Logistics Industry in 2019 and a Prospect of 2020 China's circulation economy. 2020(05) 